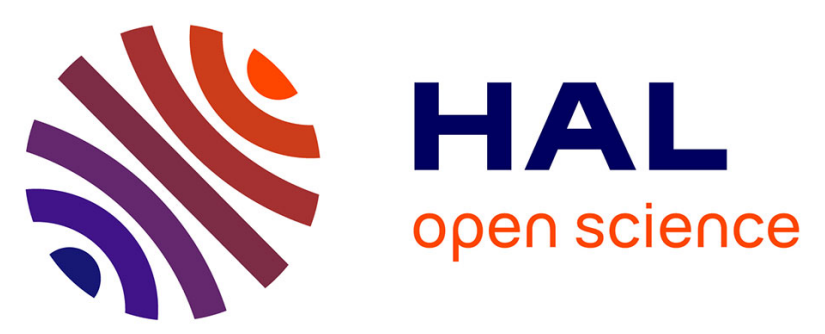

\title{
A phase I trial of lomeguatrib and irinotecan in metastatic colorectal cancer
}

A. Sabharwal, P. G. Corrie, R. S. Midgley, C. Palmer, J. Brady, P. Mortimer, A. J. Watson, G. P. Margison, M. R. Middleton

\section{- To cite this version:}

A. Sabharwal, P. G. Corrie, R. S. Midgley, C. Palmer, J. Brady, et al.. A phase I trial of lomeguatrib and irinotecan in metastatic colorectal cancer. Cancer Chemotherapy and Pharmacology, 2009, 66 (5), pp.829-835. 10.1007/s00280-009-1225-0 . hal-00568277

\section{HAL Id: hal-00568277 https://hal.science/hal-00568277}

Submitted on 23 Feb 2011

HAL is a multi-disciplinary open access archive for the deposit and dissemination of scientific research documents, whether they are published or not. The documents may come from teaching and research institutions in France or abroad, or from public or private research centers.
L'archive ouverte pluridisciplinaire HAL, est destinée au dépôt et à la diffusion de documents scientifiques de niveau recherche, publiés ou non, émanant des établissements d'enseignement et de recherche français ou étrangers, des laboratoires publics ou privés. 
Version 6, 10 December 2009

\section{A phase I trial of lomeguatrib and irinotecan in metastatic colorectal cancer.}

A Sabharwal ${ }^{1}$, PG Corrie ${ }^{2}$, RS Midgley ${ }^{1}, \mathrm{C}$ Palmer $^{2}$, J Brady ${ }^{1}, \mathrm{P} \mathrm{Mortimer}^{3}$, AJ Watson $^{4}$, GP Margison ${ }^{4}$, MR Middleton ${ }^{1}$

${ }^{1}$ University of Oxford Department of Medical Oncology, Churchill Hospital, Oxford OX3 7LJ, UK

${ }^{2}$ Oncology Centre, Addenbrooke's Hospital, Cambridge CB2 0QQ, UK

${ }^{3}$ Kudos Pharmaceuticals, 410 Cambridge Science Park, Milton Road, Cambridge. CB4 OPE, UK

${ }^{4}$ Cancer Research UK Carcinogenesis Group, University of Manchester, Paterson Institute for Cancer Research, Wilmslow Road, Manchester, M20 4BX, UK.

Keywords: Lomeguatrib, irinotecan, colorectal cancer, phase I trial, $\mathrm{O}^{6}$-methylguanineDNA-methyltransferase, DNA repair

Correspondence: Mark R. Middleton MD PhD, University of Oxford, Department of Medical Oncology, Churchill Hospital, Old Road, Oxford, OX3 7LJ, United Kingdom. Tel: +44 1865 235313; Fax: +44 1865235981.

Email: mark.middleton@medonc.ox.ac.uk

Summary: words Manuscript: words Tables: 4

Figures: 0 


\section{SUMMARY}

Background: Expression of the DNA repair protein $O^{6}$-methylguanine-DNAmethyltransferase (MGMT) correlates with resistance to irinotecan in colorectal cancer cell lines. This phase I study evaluated the maximum tolerated dose (MTD) of lomeguatrib, an inactivating pseudosubstrate of MGMT, in combination with irinotecan in patients with metastatic colorectal cancer, and assessed the safety, toxicity and clinical pharmacology of combination treatment.

Patients and Methods: Patients with metastatic colorectal cancer received lomeguatrib (10-80 mg PO) on days 1 to 5 with irinotecan $\left(250-350 \mathrm{mg} / \mathrm{m}^{2} \mathrm{IV}\right)$ on day 4 of a 21 day cycle.

Results: Twenty four patients, pre-treated with a median of 2 lines of chemotherapy, received 104 cycles of treatment. The MTD was defined as $80 \mathrm{mg} /$ day lomeguatrib with $300 \mathrm{mg} / \mathrm{m}^{2}$ irinotecan. The main toxicities observed were neutropenia and diarrhoea. 80mg/day lomeguatrib produced complete MGMT depletion in all available PBMCs and paired tumour biopsies (1 patient). There was no pharmacokinetic interaction between the drugs. In 22 patients assessable for tumour response, 1 achieved a partial response and 16 had stable disease.

Conclusion: This study defined a tolerable dose of irinotecan in combination with lomeguatrib in patients with metastatic colorectal cancer. Combination treatment gave a similar response rate to irinotecan monotherapy in this heavily pre-treated patient group. 


\section{BACKGROUND}

A third of patients with colorectal cancer present with metastatic disease which, except for a small subset with isolated hepatic involvement, cannot be cured by surgery. For all other patients treatment is palliative and involves systemic chemotherapy, possibly with additional local measures such as surgery, ablation or radiotherapy.

Irinotecan, a camptothecin derivative, acts by inhibiting topoisomerase I and has activity in stage 4 colorectal cancer in combination with fluoropyrimidines or as monotherapy [1] [2] [3] [4]. Sequential use of chemotherapies and targeted agents has improved median survival in metastatic colon cancer to more than 20 months, but response rates for second- and third-line treatments remain low [5].

Treatment with irinotecan might be improved by targeting specific mechanisms of cellular drug resistance. Pre-clinical data indicates that the DNA repair protein $O^{6}$ methylguanine-DNA-methyltransferase (MGMT) may be one such target. MGMT expression was closely correlated with sensitivity to irinotecan and its active metabolite SN-38 in a panel of 17 cell lines including 4 colorectal cancer lines [6]. Furthermore, inactivation of MGMT by the pseudosubstrate $O^{6}$-benzylguanine (O6-BG) enhanced irinotecan activity. Increasing $M G M T$ expression by transfection decreased sensitivity to irinotecan and SN-38, whereas reduced MGMT expression sensitised cells to the topoisomerase 1 inhibitor. 
Lomeguatrib is an orally bioavailable inactivator of MGMT. Regimens combining lomeguatrib with temozolomide, an $O^{6}$-alkylating agent, have been evaluated in melanoma and colorectal cancer, but results have been disappointing [8] [9] [10]. In the present report, we sought to establish the potential for lomeguatrib to enhance the activity of a different class of chemotherapeutic agent. Lomeguatrib was administered daily for 5 days, as previously used [8] [9] [10], with a single dose of irinotecan given on day 4. This dosing regimen was chosen to reflect previous dosing schedules with both agents, and to administer irinotecan in the context of MGMT depletion, as well as ensure that depletion persisted for a further 24 hours.

The primary aim of this study was to define the maximum tolerated dose (MTD) of lomeguatrib in combination with irinotecan in patients with metastatic colorectal cancer. Secondary objectives included assessing the efficacy, safety, toxicity and clinical pharmacology of combination treatment.

\section{PATIENTS AND METHODS}

\section{Inclusion and exclusion criteria}

Individuals over the age of 18 with stage 4 histologically confirmed colorectal cancer, deemed to have the potential for clinical benefit from treatment and with a life expectancy of at least 12 weeks were eligible for the study, designated PAT103. ECOG performance status of 2 or better, adequate hepatic (AST or ALT levels $\leq 2.5 \mathrm{x}$ upper 
normal limit (ULN) and total bilirubin levels $\leq 1.5 \times$ ULN), renal (serum creatinine $\leq$ $1.5 \mathrm{x}$ ULN) and bone marrow function (absolute neutrophil count $\geq 1,500 / \mathrm{mm}^{3}$ and platelet count of $\geq 100,000 / \mathrm{mm}^{3}$ ) were required.

Patients were excluded if they had recent major thoracic or abdominal surgery; chemotherapeutic or investigational agents, or radiotherapy in the preceding 4 weeks; mitomycin $\mathrm{C}$ or nitrosureas within previous 6 weeks; an active infection or significant non-malignant intercurrent illness; known central nervous metastases; a history of seizures; unresolved gastrointestinal symptoms; were pregnant or lactating; were serologically positive for hepatitis $\mathrm{B}$, hepatitis $\mathrm{C}$ or HIV; were unable to swallow capsules; or were receiving concurrent antacid medication. A negative serum pregnancy test was required in women with child-bearing potential and all patients were required to use medically approved contraceptive precautions during the study and for 4 weeks afterwards.

The study was conducted in accordance with the Principles of the International Conference on Harmonisation of Good Clinical Practice guidelines and the Declaration of Helsinki. The protocol was approved by an independent ethics committee, according to UK and local requirements. All patients enrolled in the study gave informed written consent. 


\section{Treatment}

Lomeguatrib (supplied by KuDOS Pharmaceuticals Ltd, Cambridge, UK) was orally administered at a starting dose of $10 \mathrm{mg}$ /day in the evening on days 1 to 5 of each treatment cycle, with the patient fasting for 2 hours before and after dosing. In the absence of dose limiting toxicity lomeguatrib was escalated by $100 \%$ in successive patient cohorts to a maximum of $80 \mathrm{mg} / \mathrm{day}$.

Irinotecan (Rhone-Poulenc Rorer, Vitry-sur-Seine, France) was administered by intravenous infusion over 90 minutes on the morning of day 4 at a starting dose of 350 $\mathrm{mg} / \mathrm{m}^{2}$. Early results mandated a reduction in the irinotecan dose to $250 \mathrm{mg} / \mathrm{m}^{2}$, with the option to increase to $300 \mathrm{mg} / \mathrm{m}^{2}$ if the lower dose proved tolerable with $80 \mathrm{mg} / \mathrm{day}$ lomeguatrib. Cycles were repeated every 21 days, with a total of 6 cycles planned. Concomitant treatment with cytochrome P450 inducers during the study period was not permitted.

A treatment delay of up to 2 weeks was allowed for the resolution of drug-related toxicity to grade 1 . Dose reduction of irinotecan was permitted in this event, or in the event of a dose limiting toxicity (DLT) in the preceding cycle. Patients could be withdrawn from the study for progressive disease, unacceptable toxicity, serious violation of the study protocol, or withdrawal of consent.

At least 3 patients were treated at each dose level and any patient withdrawn before day 21 was replaced. The first patient at each dose level was observed for at least 1 week following irinotecan administration, i.e. day 11, before enrolment of subsequent patients 
at that dose level. All 3 patients at a dose level were required to complete one treatment cycle before a decision to dose escalate lomeguatrib or irinotecan could be made. DLT was defined as any of the following study drug related events experienced during cycle 1: grade 4 haematological toxicity lasting >5 days; grade 3 or 4 febrile neutropenia; grade 3 or 4 non-haematological toxicity including diarrhoea, nausea or vomiting despite adequate treatment. Patients were followed up for 30 days after the last dose of study drug. If 1 of 3 patients at a dose level developed a DLT, up to 3 additional patients were treated at that dose level. If 1 of the 3 additional patients developed a DLT, dose escalation ceased and a total of 6 patients were treated at the preceding dose level. This lower dose was defined as the maximum tolerated dose (MTD) unless $\geq 2$ of 6 patients developed a DLT.

\section{Toxicity and response evaluation}

Pre-treatment evaluations included a complete medical history and physical examination, full blood count, biochemical profile including carcino-embryonic antigen (CEA), urinalysis and electrocardiogram. CT scans were performed to evaluate tumour sites, using RECIST, prior to commencing treatment, after 2 complete cycles, and at the end of 6 cycles of treatment. Toxicities were evaluated at least weekly during the study period and toxicities graded according to the National Cancer Institute Common Toxicity Criteria version 2. 


\section{Pharmacodynamics}

Blood samples for peripheral blood mononuclear cell (PBMC) isolation and MGMT assessment were obtained prior to treatment on day 1 of cycle 1 , prior to irinotecan dosing on day 4 and at the end of treatment, on day 6. Eight $\mathrm{mL}$ of blood were taken in each of 2 tubes containing $320 \mu$ mol EDTA. Optional tumour core biopsies were obtained on day 1 pre-treatment and post-treatment on day 6. Tumour biopsies were taken under local anaesthetic, immediately frozen on dry ice and stored at $-70{ }^{\circ} \mathrm{C}$ before determination of MGMT activity according to the method of [11].

\section{Pharmacokinetics}

Five $\mathrm{mL}$ venous blood was drawn into lithium heparin vacutainers for determination of lomeguatrib and 8-hydroxy-lomeguatrib concentration immediately prior to the start of the irinotecan infusion (approximately 12 hours after the day 3 dose of lomeguatrib). Venous blood samples were also collected prior to the start of the irinotecan infusion, and immediately, 30 minutes, 1, 2, 4, 6 to 8 and 24 hours after the end of infusion to quantify plasma levels of irinotecan and its major circulating metabolite SN-38. Plasma drug concentrations were determined by high performance liquid chromatography with tandem mass spectrometric detection (HPLC-MS-MS). Data collection and peak area integration were performed using Analyst software (version 1.3.1) associated with the mass spectrometer. Standard regression and quantification were performed using Watson LIMS (version 7.0).

\section{RESULTS}


Twenty-five patients were enrolled in the study at 2 centres. One patient, enrolled into cohort 1 , withdrew their consent prior to receiving treatment. The characteristics of the other 24 patients are summarized in table 1. All patients had received previous chemotherapy (median 2 lines). All 24 patients were evaluable for toxicity following treatment with lomeguatrib and irinotecan, and 22 were evaluable for tumour response.

\section{Dose escalation and extent of exposure}

Two of the 3 patients treated in cohort 1 with irinotecan $350 \mathrm{mg} / \mathrm{m}^{2}$ and lomeguatrib 10 $\mathrm{mg}$ /day experienced grade 3 diarrhoea. One of these patients was admitted as an emergency with a 3 day history of severe diarrhoea, having ignored instructions to contact the study centre in that event, and grade 4 neutropenia. Despite aggressive resuscitation the patient died from presumed neutropenic sepsis. For subsequent cohorts $250 \mathrm{mg} / \mathrm{m}^{2}$ irinotecan was given with escalating lomeguatrib doses (cohorts 2, 3, 4, and 5) and escalated to $300 \mathrm{mg} / \mathrm{m}^{2}$ at the highest lomeguatrib dose (cohort 6 , see table 2). One further dose-limiting toxicity was observed in the study: 1 of 3 patients in cohort 4 (lomeguatrib $40 \mathrm{mg}$ and irinotecan $250 \mathrm{mg} / \mathrm{m}^{2}$ ) had grade 4 neutropenia for longer than 5 days resulting in expansion of the cohort to 6 patients with no additional DLTs. The MTD for the combination was determined to be $300 \mathrm{mg} / \mathrm{m}^{2}$ irinotecan with $80 \mathrm{mg} /$ day lomeguatrib.

A total of 104 cycles (median 6 cycles per patient) of lomeguatrib and irinotecan were administered across the study. In keeping with the protocol there were no dose reductions of lomeguatrib, but 5 patients required irinotecan dose reductions of 50 
$\mathrm{mg} / \mathrm{m}^{2}$ (in 2 patients two dose reductions were needed) for haematological toxicity and/or diarrhoea. Four treatment cycles were delayed to allow for recovery of neutropaenia.

\section{Safety}

Adverse events were as anticipated for irinotecan (table 3). The most significant toxicities were neutropaenia and diarrhoea, although nausea, fatigue, anorexia and alopecia were common. Neutropaenia was recorded in a third of treatment cycles, but in only 3 patients was this of grade 3 or 4 severity. There was 1 episode of neutropaenic sepsis (as described above) and 1 of febrile neutropaenia without sepsis. Diarrhoea occurred in $46 \%$ of cycles, affecting four fifths of the patients, but was grade 3 or 4 severity in only five individuals. No significant cumulative toxicities were seen, and toxicities all resolved on cessation of treatment.

\section{Efficacy}

Two patients were not evaluable for response since they did not complete cycle 1 of treatment. One partial response was documented and 16 patients had stable disease, with the other 5 progressing on treatment. The partial response was seen in an irinotecan naïve patient, previously treated with oxaliplatin-based therapy. Median time to progression was 4.0 months (range 1.2 to 16.2 months). Median overall survival was 5.4 months (0.4 to 16.2 months). 


\section{Pharmacokinetics}

Lomeguatrib plasma concentration 12 hours after dosing on day 3 was available for 21 of the 24 patients. This confirmed no detectable lomeguatrib at the time of irinotecan administration. Irinotecan and SN-38 plasma concentrations were obtained for 22 of the patients (table 4). Maximum plasma concentrations were seen at the end of infusion after which concentrations declined in a biphasic fashion. The terminal half-life of irinotecan was 5-7h, but it was not possible to derive the terminal half-life for SN38.

\section{Pharmacodynamics}

MGMT activity was detectable in the 22 available pre-treatment PBMC samples; mean activity $11.7 \mathrm{fmol} / \mu \mathrm{g}$ DNA (range $6.2-22.9 \mathrm{fmol} / \mu \mathrm{g}$ DNA) but not detectable in any of the 17 pre-irinotecan (day 4) or 13 end of treatment (day 6) samples. Similarly, MGMT activity was detected in the single pre-treatment tumour biopsy ( $6.9 \mathrm{fmol} / \mu \mathrm{g}$ DNA) but not in the corresponding end of treatment sample.

\section{DISCUSSION}

The patients treated in this study, a representative population in terms of their age, performance status and prior therapies, did not tolerate the standard irinotecan dose of $350 \mathrm{mg} / \mathrm{m}^{2}$ when combined with $10 \mathrm{mg} /$ day lomeguatrib, indicating a biological effect of the latter agent. Irinotecan at $250 \mathrm{mg} / \mathrm{m}^{2}$ or $300 \mathrm{mg} / \mathrm{m}^{2}$ was well tolerated across a 
range of lomeguatrib doses including at $80 \mathrm{mg} /$ day, a dose which has been shown reliably to deplete colorectal tumour MGMT [12].

$\mathrm{T}_{\max }$ and $\mathrm{C}_{\max }$ for irinotecan and $\mathrm{SN}-38$ were consistent with prior studies, indicating no interaction between lomeguatrib and irinotecan [13]. The area under the concentrationtime curve for both irinotecan and $\mathrm{SN}-38$ was lower than some previous reports, but this is a consequence of the reduced duration of sampling in our study - as has been described previously [14].

The spectrum of toxicities observed was as expected for irinotecan. The incidence of grade 3 and 4 diarrhoea was very similar to that previously reported with single agent irinotecan in metastatic colorectal cancer, affecting $21 \%$ of patients compared with $21 \%$ and $22 \%$ [15] [16]. Once the dose of irinotecan was reduced the incidence of grade 3 or 4 neutropaenia, at $10 \%$, was lower than that previously reported for irinotecan alone, at $22 \%$ and $14 \%$. The inability to combine irinotecan at full dose with lomeguatrib was not surprising, as the latter has been reported to increase haematological toxicity when used in combination with other myelotoxic chemotherapeutic agents [8]. Complete inactivation of PBMC MGMT was seen at the lowest lomeguatrib dose administered. Since expression of the repair protein in PBMCs is very similar to that in myeloid precursor cells, this could explain why increasing doses of lomeguatrib were not associated with increasing myelotoxicity. In general, haematological and nonhaematological side-effects were readily managed and despite these toxicities, 
compliance with treatment was good with only one patient discontinuing treatment due to unacceptable side effects. No lomeguatrib-specific toxicity was encountered.

Combination treatment with irinotecan and lomeguatrib yielded only 1 partial response. These patients had all received prior chemotherapy with a median 2 (range 1 to 6) regimens. Eleven (46\%) had previously been treated with irinotecan. The responding patient was irinotecan-naïve, so evidence for the reversal of resistance to the topoisomerase inhibitor was not seen. In this setting, in which most patients were receiving third-line treatment, a response rate of $4-6 \%$ would be expected, equivalent to 1 responder in a study of this size [4]. Thus, lomeguatrib did not appear to improve patient outcomes, but this might better be assessed in patients receiving irinotecan as part of first or second line treatment.

The MTD was defined as irinotecan $300 \mathrm{mg} / \mathrm{m}^{2}$ with lomeguatrib $80 \mathrm{mg} /$ day for 5 days. It might be possible to escalate the dose of lomeguatrib used in combination with irinotecan further. However, a single dose of $80 \mathrm{mg}$ lomeguatrib inactivated over $96.5 \%$ of MGMT in colorectal tumours at 12 hours [12] so that one might reasonably anticipate complete depletion of MGMT in tumour at the time irinotecan was administered in this study. Greater duration of MGMT depletion, so as to ensure no recovery in MGMT activity before replication, might also be considered. However, such prolonged lomeguatrib administration was associated with much greater myelotoxicity, without improvement in efficacy, when combined with temozolomide 
[17]. This might not be the case with irinotecan since topoisomerase 1 inhibitors do not generate DNA alkylation damage.

Addition of a methylating agent, such as temozolomide, to combination treatment with lomeguatrib and irinotecan could also be explored. Pre-clinical data show that treatment with an $O^{6}$-alkylating agent prior to irinotecan increases its cytotoxicity in a schedule dependent manner [18] [19]. The basis of this effect is an enhancement in topoisomerase 1 mediated DNA strand cleavage in the presence of $O^{6}$-methylguanine and a decreased rate of religation. $O^{6}$-alkylating agent therapy therefore induces top 1DNA cleavage complexes. Such complexes are susceptible to trapping by topoisomerase 1 inhibitors resulting in DNA damage, which is ultimately cytotoxic. The presence of $O^{6}$-methlyguanine in DNA enhances topoisomerase 1 inhibitor cytotoxicity. Depletion of MGMT, which repairs $O^{6}$-methylguanine, considerably enhances the cytotoxicity of topoisomerase 1 inhibitors in cells. This enhancement appears to be independent of the cytotoxicity of the DNA lesion itself in that it is observed in mismatch repair deficient (i.e $O^{6}$-methylguanine tolerant) cells. The effect of MGMT on this interaction has not yet been fully elucidated, but in vitro studies have shown that adding $O^{6}$-benzylguanine to combination treatment with temozolomide and irinotecan results in a significant reduction in the growth of human tumour xenografts compared with either temozolomide or irinotecan alone or together [20]. 
A number of clinical studies have reported disappointing results for $O^{6}$-alkylating agent and irinotecan combination treatment, with no improvement in efficacy of over irinotecan alone, but these have used regimens in which the topoisomerase inhibitor was given first [21] [22]. More encouraging results have been seen when drug scheduling is optimised in accordance with pre-clinical data and the alkylating agent is administered prior to irinotecan. For example, in a phase I study in recurrent malignant glioma, patients were given temozolomide (days 1-5) then irinotecan (day 6), and 10 of 32 (31\%) achieved a complete or partial response [23].

Although responses to high dose therapy with the chlorethylating agent BCNU have been reported in patients with metastatic colorectal cancer [24], combination treatment with lomeguatrib and temozolomide was found to be ineffective in this patient group [9]. Temozolomide may still have a role in colorectal cancer chemotherapy through the effects of $O^{6}$-methylguanine on topoisomerase I activity and the efficacy of irinotecan as described above. However, given the overlapping toxicity profiles for temozolomide and irinotecan, in particular haematological toxicity, any future studies will require careful design.

In conclusion, this phase I study successfully identified doses of lomeguatrib and irinotecan for use in combination therapy in patients with metastatic colorectal cancer. While the focus of colorectal cancer systemic therapy has now shifted towards integration of targeted biological agents with cytotoxic chemotherapy, exploration of 
this novel regimen could be considered in patients receiving first or second line irinotecan.

\section{Acknowledgements}

This trial was sponsored by Kudos Pharmaceuticals, a subsidiary of Astrazeneca. MM is supported by the NIHR Biomedical Research Centre, Oxford. 


\section{REFERENCES}

1. Douillard JY, Cunningham D, Roth AD, Navarro M, James RD, Karasek P, et al. Irinotecan combined with fluorouracil compared with fluorouracil alone as first-line treatment for metastatic colorectal cancer: a multicentre randomised trial. Lancet 2000;355(9209):1041-7.

2. Kohne $\mathrm{CH}$, van Cutsem E, Wils J, Bokemeyer C, El-Serafi M, Lutz MP, et al. Phase III study of weekly high-dose infusional fluorouracil plus folinic acid with or without irinotecan in patients with metastatic colorectal cancer: European Organisation for Research and Treatment of Cancer Gastrointestinal Group Study 40986. J Clin Oncol 2005;23(22):4856-65.

3. Saltz LB, Cox JV, Blanke C, Rosen LS, Fehrenbacher L, Moore MJ, et al. Irinotecan plus fluorouracil and leucovorin for metastatic colorectal cancer. Irinotecan Study Group. N Engl J Med 2000;343(13):905-14.

4. Rowland KM, Pitot HC, Sargent DJ, Philip PA, Mitchell EP, Mailliard JA, et al. Results of 3rd line therapy on N9841: a randomized phase III trial of oxaliplatin/5-fluorouracil $(5 \mathrm{FU}) /$ leucovorin (FOLFOX4) versus irinotecan (CPT-11) in patients (pts) with advanced colorectal cancer (CRC) previously treated with prior 5FU chemotherapy. In: ASCO Annual Meeting Proceedings; 2005 June 1: Journal of Clinical Oncology; 2005. p. Abstr no. 3519.

5. Tournigand C, Andre T, Achille E, Lledo G, Flesh M, Mery-Mignard D, et al. FOLFIRI followed by FOLFOX6 or the reverse sequence in advanced colorectal cancer: a randomized GERCOR study. J Clin Oncol 2004;22(2):229-37.

6. Okamoto R, Takano H, Okamura T, Park JS, Tanimoto K, Sekikawa T, et al. O(6)methylguanine-DNA methyltransferase (MGMT) as a determinant of resistance to camptothecin derivatives. Jpn J Cancer Res 2002;93(1):93-102.

7. Ranson M, Middleton MR, Bridgewater J, Lee SW, Dawson M, Jowle D, et al. Lomeguatrib, a Potent Inhibitor of O6-alkylguanine-DNA-Alkyltransferase: Phase I Safety, Pharmacodynamic, and Pharmacokinetic Trial and Evaluation in Combination with Temozolomide in Pateints with Advanced Solid Tumours. Clin Cancer Res 2006;12(5):(in press).

8. Ranson M, Hersey P, Thompson D, Beith J, McArthur GA, Haydon A, et al. Randomized trial of the combination of lomeguatrib and temozolomide compared with temozolomide alone in chemotherapy naive patients with metastatic cutaneous melanoma. J Clin Oncol 2007;25(18):2540-5.

9. Khan OA, Ranson M, Michael M, Olver I, Levitt NC, Mortimer P, et al. A phase II trial of lomeguatrib and temozolomide in metastatic colorectal cancer. $\mathrm{Br} J$ Cancer 2008;98(10):1614-8.

10. Ranson M, Middleton MR, Bridgewater J, Lee SM, Dawson M, Jowle D, et al. Lomeguatrib, a potent inhibitor of 06-alkylguanine-DNA-alkyltransferase: phase I safety, pharmacodynamic, and pharmacokinetic trial and evaluation in combination with temozolomide in patients with advanced solid tumors. Clin Cancer Res 2006;12(5):1577-84.

11. Watson AJ, Margison GP. O6-alkylguanine-DNA alkyltransferase assay. Methods Mol Biol 2000;152:49-61. 
12. Sabharwal A. Inhibition of O6-methylguanine DNA methyltransferase (MGMT) in solid tumors by lomeguatrib. In: ASCO annual meeting; 2008 May 20; Chicago: J Clin Oncol; 2008. p. abstr 3597.

13. Pitot HC, Goldberg RM, Reid JM, Sloan JA, Skaff PA, Erlichman C, et al. Phase I dosefinding and pharmacokinetic trial of irinotecan hydrochloride (CPT-11) using a onceevery-three-week dosing schedule for patients with advanced solid tumor malignancy. Clin Cancer Res 2000;6(6):2236-44.

14. Mathijssen RH, Verweij J, Loos WJ, de Bruijn P, Nooter K, Sparreboom A. Irinotecan pharmacokinetics-pharmacodynamics: the clinical relevance of prolonged exposure to SN-38. Br J Cancer 2002;87(2):144-50.

15. Cunningham D, Pyrhonen S, James RD, Punt CJ, Hickish TF, Heikkila R, et al. Randomised trial of irinotecan plus supportive care versus supportive care alone after fluorouracil failure for patients with metastatic colorectal cancer. Lancet 1998;352(9138):1413-8.

16. Rougier P, Van Cutsem E, Bajetta E, Niederle N, Possinger K, Labianca R, et al. Randomised trial of irinotecan versus fluorouracil by continuous infusion after fluorouracil failure in patients with metastatic colorectal cancer. Lancet 1998;352(9138):1407-12.

17. Kefford RF, Thomas NP, Corrie PG, Palmer C, Abdi E, Kotasek D, et al. A phase I study of extended dosing with lomeguatrib with temozolomide in patients with advanced melanoma. Br J Cancer 2009;100(8):1245-9.

18. Pourquier P, Waltman JL, Urasaki Y, Loktionova NA, Pegg AE, Nitiss JL, et al. Topoisomerase I-mediated cytotoxicity of N-methyl-N'-nitro-N-nitrosoguanidine: trapping of topoisomerase I by the 06-methylguanine. Cancer Res 2001;61(1):53-8.

19. Houghton PJ, Stewart CF, Cheshire PJ, Richmond LB, Kirstein MN, Poquette CA, et al. Antitumor activity of temozolomide combined with irinotecan is partly independent of 06-methylguanine-DNA methyltransferase and mismatch repair phenotypes in xenograft models. Clin Cancer Res 2000;6(10):4110-8.

20. Friedman HS, Keir S, Pegg AE, Houghton PJ, Colvin OM, Moschel RC, et al. O6benzylguanine-mediated enhancement of chemotherapy. Mol Cancer Ther 2002;1(11):943-8.

21. Quinn JA, Reardon DA, Friedman AH, Rich JN, Sampson JH, Vredenburgh J, et al. Phase 1 trial of irinotecan plus $B C N U$ in patients with progressive or recurrent malignant glioma. Neuro-oncol 2004;6(2):145-53.

22. Reardon DA, Quinn JA, Rich JN, Gururangan S, Vredenburgh J, Sampson JH, et al. Phase 2 trial of BCNU plus irinotecan in adults with malignant glioma. Neuro-oncol 2004;6(2):134-44.

23. Gruber ML, Buster WP. Temozolomide in combination with irinotecan for treatment of recurrent malignant glioma. Am J Clin Oncol 2004;27(1):33-8.

24. Phillips GL, Fay JW, Herzig GP, Herzig RH, Weiner RS, Wolff SN, et al. Intensive 1,3bis(2-chloroethyl)-1-nitrosourea (BCNU), NSC \#4366650 and cryopreserved autologous marrow transplantation for refractory cancer. A phase I-II study. Cancer 1983;52(10):1792-802. 


\begin{tabular}{lr}
\hline Number of patients & 24 \\
\hline & \\
Median age (range) & $62.5(40-75)$ \\
Gender (Male/Female) & $15 / 9$ \\
PS (0/1) & $21 / 3$ \\
Extent of disease & \\
1 organ involved & 4 \\
2 & 9 \\
$\geq 3$ & 11 \\
Liver & 20 \\
Lung & 19 \\
Other viscera & 15 \\
& \\
Prior chemotherapy & \\
Irinotecan-based & 11 \\
Oxaliplatin \& 5-FU/capecitabine & 21 \\
5-FU/capecitabine & 10 \\
\end{tabular}


Table 2. Drug doses for each cohort

\begin{tabular}{lccc}
\hline Cohort & $\begin{array}{c}\text { Irinotecan dose } \\
\left(\mathrm{mg} / \mathrm{m}^{2}\right)\end{array}$ & $\begin{array}{l}\text { Lomegatrib dose } \\
(\mathrm{mg} / \text { day })\end{array}$ & pumber of \\
\hline 1 & 350 & 10 & 3 \\
2 & 250 & 10 & 3 \\
3 & 250 & 20 & 3 \\
4 & 250 & 40 & 6 \\
5 & 250 & 80 & 3 \\
6 & 300 & 80 & 6 \\
\hline
\end{tabular}


Table 4. Derived pharmacokinetic parameters for irinotecan and SN-38

\begin{tabular}{|c|c|c|c|c|c|c|}
\hline \multirow[t]{2}{*}{ Irinotecan dose } & \multicolumn{2}{|c|}{$\begin{array}{c}250 \mathrm{mg} / \mathrm{m}^{2} \\
(\mathrm{~N}=14)\end{array}$} & \multicolumn{2}{|c|}{$\begin{array}{c}300 \mathrm{mg} / \mathrm{m}^{2} \\
(\mathrm{~N}=5)\end{array}$} & \multicolumn{2}{|c|}{$\begin{array}{c}350 \mathrm{mg} / \mathrm{m}^{2} \\
(\mathrm{~N}=3)\end{array}$} \\
\hline & Irinotecan & SN-38 & Irinotecan & SN-38 & Irinotecan & $\mathrm{SN}-38$ \\
\hline $\mathrm{C}_{\max }(\mathrm{ng} / \mathrm{ml})$ & 2530 & 40.9 & 3510 & 35.7 & 4190 & 36.7 \\
\hline$(\mathrm{CV} \%)$ & (28) & (53) & $(32)$ & $(60)$ & (34) & (38) \\
\hline $\mathrm{T}_{\max }(\mathrm{h})$ & 1.72 & 1.72 & 1.68 & 1.76 & 2.37 & 1.87 \\
\hline (range) & $(1.53-2.65)$ & $(1.53-2.58)$ & $(1.65-2.33)$ & $(1.67-2.67)$ & $(1.80-2.38)$ & $(1.80-1.90)$ \\
\hline AUC0-t (ng.h/ml) & 14.9 & 260.9 & 17.4 & 303.5 & 33.5 & 395.3 \\
\hline$(\mathrm{CV} \%)$ & (32) & (62) & (12) & $(62)$ & $(52)$ & (38) \\
\hline
\end{tabular}

$\mathrm{C}_{\max }$, peak plasma concentration; $\mathrm{T}_{\max }$, time to peak plasma concentration; AUC, area under plasma concentration-time curve; $\mathrm{CV}$, coefficient of variation 
Table 3. Commonest treatment related toxicities*

All adverse events

Grade 3/4

adverse events

\begin{tabular}{|c|c|c|c|c|c|}
\hline \multirow{2}{*}{ Irinotecan dose } & Total & $350 \mathrm{mg} / \mathrm{m}^{2}$ & $250 \mathrm{mg} / \mathrm{m}^{2}$ & $300 \mathrm{mg} / \mathrm{m}^{2}$ & \multirow{2}{*}{$\begin{array}{c}\text { All } \\
\mathrm{N}=24(\%)\end{array}$} \\
\hline & $\mathrm{N}=24(\%)$ & $\mathrm{N}=3(\%)$ & $\mathrm{N}=15(\%)$ & $\mathrm{N}=6(\%)$ & \\
\hline Neutropaenia & $5(21)$ & $2(67)$ & $2(13)$ & $1(17)$ & $3(13)$ \\
\hline Anaemia & $6(25)$ & $1(33)$ & $5(33)$ & 0 & $1(4)$ \\
\hline Nausea & $11(46)$ & $2(67)$ & $7(47)$ & $2(33)$ & \\
\hline Vomiting & $9(38)$ & $1(33)$ & $4(27)$ & $4(67)$ & $2(8)$ \\
\hline Constipation & $4(17)$ & $1(33)$ & $3(20)$ & 0 & \\
\hline Diarrhoea & $19(79)$ & $2(67)$ & $12(80)$ & $5(87)$ & $5(21)$ \\
\hline Fatigue & $16(67)$ & $2(67)$ & $11(73)$ & $3(50)$ & $2(8)$ \\
\hline Cough & $4(17)$ & 0 & $3(20)$ & $1(17)$ & \\
\hline Anorexia & $11(46)$ & $2(67)$ & $6(40)$ & $3(50)$ & \\
\hline Headache & $7(29)$ & 0 & $5(33)$ & $2(33)$ & \\
\hline Fever & $4(17)$ & 0 & $4(27)$ & 0 & \\
\hline Abdominal pain & $8(33)$ & $1(33)$ & $5(33)$ & $2(33)$ & \\
\hline Alopecia & $20(83)$ & $3(100)$ & $13(65)$ & $8(89)$ & \\
\hline
\end{tabular}

*adverse events considered possibly, probably or highly probably related to treatment occurring in $15 \%$ or more patients 